\title{
FUEL TANK INTEGRITY RESEARCH: FUEL TANK ANALYSES AND TEST PLANS
}

\author{
Karina Jacobsen \\ Patricia Llana \\ Michael Carolan \\ Laura Sullivan \\ Volpe National Transportation Systems Center \\ United States Department of Transportation \\ Cambridge, Massachusetts, USA
}

\section{ABSTRACT}

The Federal Railroad Administration's Office of Research and Development is conducting research into fuel tank crashworthiness. Fuel tank research is being performed to determine strategies for increasing the fuel tank impact resistance to mitigate the threat of a post-collision or postderailment fire. In accidents, fuel tanks are subjected to dynamic loading, often including a blunt or raking impact from various components of the rolling stock or trackbed. Current design practice requires that fuel tanks have minimum properties adequate to sustain a prescribed set of static load conditions. Current research is intended to increase understanding of the impact response of fuel tanks under dynamic loading. Utilizing an approach that has been effective in increasing the structural crashworthiness of railcars, improved strategies can be developed that will address the types of loading conditions which have been observed to occur in a collision or derailment event.

U.S. rail accident surveys reveal the types of threats fuel tanks are exposed to during collisions, derailments and other events. These include blunt impacts and raking impacts to any exposed side of the tank. This research focuses on evaluating dynamic impact conditions for fuel tanks and investigating how fuel tank design features affect the collision performance of the tank. Research activities will include analytical modeling of fuel tanks under dynamic loading conditions, dynamic impact testing of fuel tank articles, and recommendations for improved fuel tank protection strategies.

This paper describes detailed finite element analyses that have been developed to estimate the behavior of three different fuel tanks under a blunt impact. These analyses are being used to understand the deformation behavior of different tanks and prepare for planned testing of two of these tanks. Observations are made on the influence of stiffeners, baffles, and other design details relative to the distance from impact.

This paper subsequently describes the preliminary test plans for the first set of tests on conventional passenger locomotive fuel tanks. The first set of tests is designed to measure the deformation behavior of the fuel tanks with a blunt impact of the bottom face of the tanks. The test articles are fuel tanks from two retired EMD F-40 locomotives. A blunt impact will be conducted by securing the test articles to a crash wall and impacting them with an indenter extending from a test cart. This set of tests is targeted for late summer 2013 at the Transportation Technology Center (TTC) in Pueblo, Colorado.

Both blunt and raking impact conditions will be evaluated in future research. Tests are also being planned for DMU fuel tanks under dynamic loads.

\section{INTRODUCTION}

The fuel tank crashworthiness research is being conducted as part of the Federal Railroad Administration's (FRA's) Equipment Safety Research program. The methodology for crashworthiness research is illustrated in Figure 1.

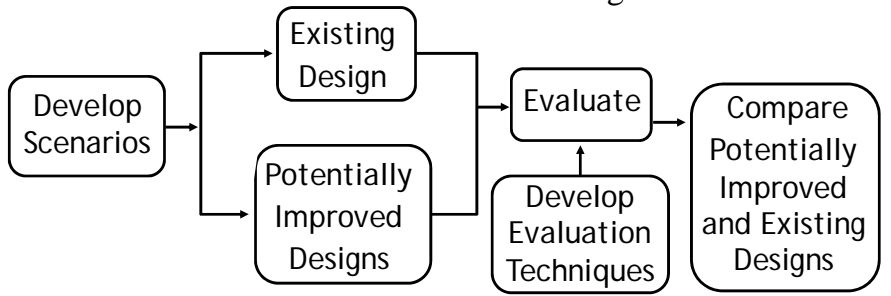

Figure 1. Flow diagram, crashworthiness research methodology

1

This material is declared a work of the U.S. Government and is not subject to copyright protection in the United States. Approved for public release; distribution is unlimited. 
Review of passenger train accidents, derailments and other events help identify the causal mechanisms that lead to injuries and fatalities in rail travel. Gathering and organizing this information helps to identify threats and evaluate the effectiveness of current crashworthiness and emergency preparedness regulations.

The event of a fuel tank rupture in a train collision or derailment may lead to fire which presents a secondary threat to the survivability of passengers and crew. The incident shown below in Figure 2 resulted in fire when a locomotive-led passenger train struck a lowboy trailer at a grade-crossing causing the locomotive to derail, during which the fuel tank was punctured.

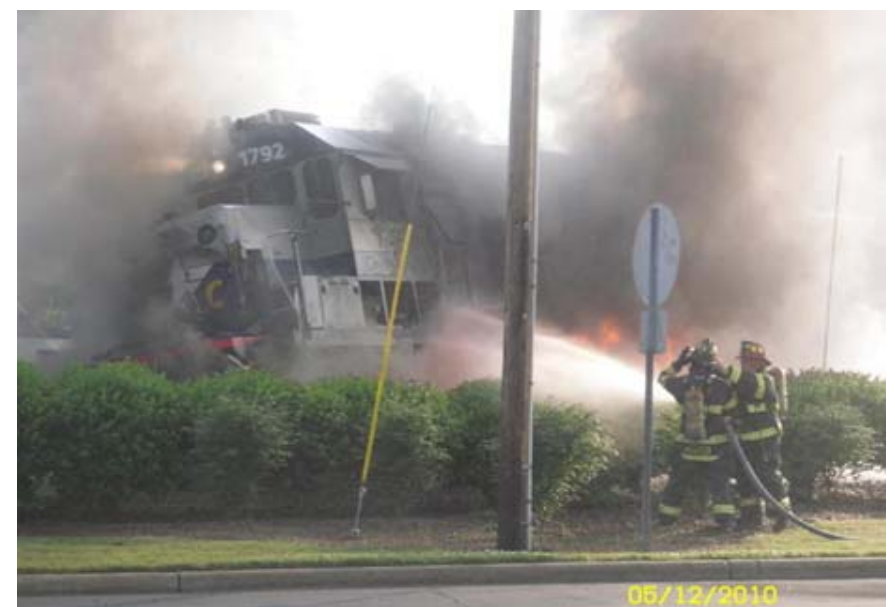

Figure 2. Grade Crossing Collision, Membane, NC, May 12, 2010 [1]

Through accident investigations and a general survey of rail incidents in the U.S., the causes and results of fuel tank rupture in rail accidents have been identified and categorized into two general loading conditions [2]. Table 1 summarizes the results of the accident survey conducted in reference 1.

Table 1. Locomotive collision scenarios and related fuel tank collision modes.

\begin{tabular}{|l|l|l|}
\hline & Collision Scenario & Collision Mode \\
\hline 1 & $\begin{array}{l}\text { Impact with Surrounding Railcar } \\
\text { Component }\end{array}$ & Blunt Impact to End of Tank \\
\hline 2 & Oblique Impact with Another Railcar & $\begin{array}{l}\text { Raking of Side of Tank OR } \\
\text { Blunt Impact to Side of Tank }\end{array}$ \\
\hline 3 & $\begin{array}{l}\text { Rollover and Impact with Another } \\
\text { Railcar }\end{array}$ & Blunt Impact to Bottom of Tank \\
\hline 4 & Grounding & $\begin{array}{l}\text { Raking of Bottom or Side of Tank OR } \\
\text { Blunt Impact to Side of Tank }\end{array}$ \\
\hline 5 & Impact with Rail or Other Object & Blunt Impact to Bottom of Tank \\
\hline
\end{tabular}

The table highlights that all exposed sides of the fuel tank can be vulnerable to impacts during the possible range of collision or derailment events. The ends of fuel tanks are most typically struck by adjacent trucks and surrounding structural components or mounted equipment. The bottoms of fuel tanks are exposed when the locomotive comes off the tracks, rolls over and is then struck by other rail vehicles or debris. The incidents reviewed also indicate that fuel tanks may be challenged by a combination of collision modes in a single incident. In summary, the types of loading sustained by the fuel tank can be generally reduced to two categories: blunt impacts or raking impacts.

A fuel tank testing program has been outlined to evaluate existing fuel tank designs under the identified impacts and to develop strategies for enhancing fuel tank integrity under such impacts. The purpose of testing conventional fuel tanks is to establish a baseline level of performance and to characterize the loading parameters that deform a tank and can lead to the undesirable consequence of fuel tank rupture.

To aid in evaluating rail component crashworthiness, computer models help to characterize how the fuel tank deforms and identify the significant parameters of loading conditions. Parametric studies can be conducted to help plan for tests and determine the test requirements. Post-test, the model is revised if needed, and then serves as a tool for evaluating other impact scenarios.

\section{BLUNT IMPACT TEST PLANNING}

The first stage of testing of conventional fuel tanks is planned to take place at the Technology Transportation Center (TTC) in Pueblo, Colorado. Two types of impacts will be tested in evaluating conventional tanks. Of these tests this paper focuses on the initial tests of two conventional passenger locomotive fuel tanks. The objective is to examine the gross response of the fuel tanks to a blunt impact. Finite element (FE) analysis is being used to assist in planning these tests. FE models of the candidate fuel tanks have been constructed. These models have been executed to investigate the effects of different impactor sizes, different impactor speeds and the influence of the impact location on the response of the tank. A variety of models used to plan for the tests and selected results are described in the following sections.

\section{Loading Conditions}

The loading condition that will be evaluated in the first tests of this research program is a blunt impact to the bottom face of a locomotive fuel tank. The bottom face was selected as the impacted location for several reasons. For a typical locomotive fuel tank mounted beneath the underframe of the locomotive, the bottom face of the fuel tank is the area of the tank with the smallest clearance above the top-of-rail and ground. The surface of the fuel tank is also quite large, which increases the likelihood that a piece of debris kicked up from beneath the locomotive will strike this surface. Finally, in the case of a derailment where the locomotive has rolled over, the bottom surface of the fuel tank is vulnerable to impacts from other pieces of equipment involved in the derailment.

Typically, locomotive fuel tanks include several lateral and longitudinal baffles. These baffles serve multiple purposes. By dividing the interior of the locomotive into compartments, they limit fuel sloshing that can occur during operation due to the acceleration and deceleration of the locomotive. Because these baffles are attached to the outer walls of the fuel tank, they also contribute to the overall stiffness of the tank. For a load

This material is declared a work of the U.S. Government and is not subject to copyright protection in the United States. Approved for public release; distribution is unlimited. 
condition where the locomotive's weight is resting on the fuel tank (e.g. following a derailment), the weight is supported not only by the outer shell of the fuel tank but also by the internal baffles.

Because the baffles divide the fuel tank into several internal compartments, the effective fuel tank stiffness in any local area will depend on that area's proximity to one or more baffles. One investigation undertaken by the current research program is to examine the effect of baffle proximity on the behavior of the tank under a given impact loading condition. In support of that goal, several finite element analyses were performed for various impactor sizes and locations on the bottom of the fuel tank.

In considering a loading condition to subject the baseline locomotive fuel tank to, it was desired that the loading condition be repeatable across multiple fuel tank test articles and be indicative of the ability of the fuel tank to sustain load leading up to rupture. For an impact striking the bottom of a fuel tank, there are several different loading conditions that can occur based upon where on the physical tank the impact occurs. The tank may be struck adjacent to any of the outer walls, near a corner, or in its center. Additionally, because the interior of the tank contains various baffles, the response of the tank may be dependent on whether the impact occurs on top of a baffle, adjacent to a baffle, or far from any baffles. An exemplar fuel tank, with major features indicated, is shown upside-down and in section in Figure 4. Note that the baffles in this image are shown as solid plates, chosen to represent the stiffest baffles possible. In an actual fuel tank, the baffles contain cutouts to permit fuel to flow from one compartment of the tank to another. Depending on the size and location of these cutouts, the baffles may be significantly less stiff than the solid baffles shown in the figure.

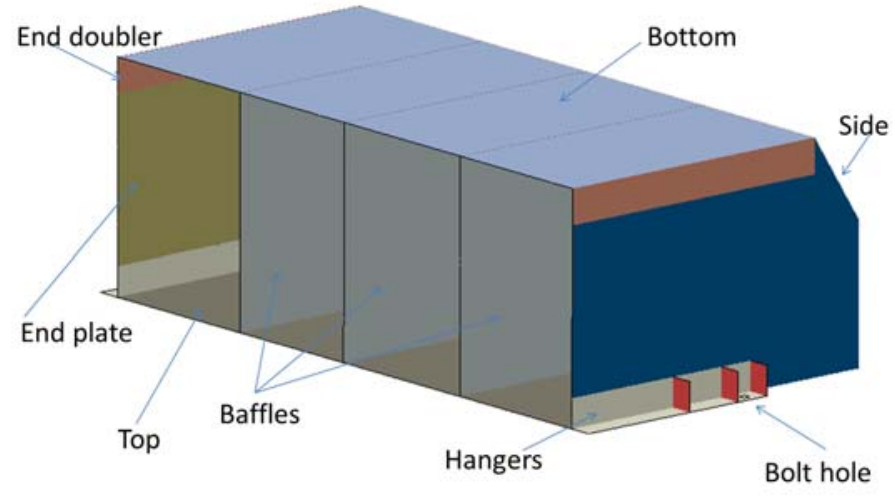

Figure 3. Locomotive fuel tank with features indicated

\section{ANALYSES}

In order to examine the effects of striking a fuel tank at various locations and with various impactor geometries, a series of finite element analyses were undertaken. Three fuel tanks were constructed based on measured and documented geometry and material properties. The fuel tanks are different in size, shape and material properties. The purpose of these initial analyses was to characterize the deformation of the tank under a blunt impact to the bottom of the tank. A series of analyses were conducted to characterize the influence of different size impactors, varying weight of the impactor and location of the impact on the bottom of the tank.

\section{FRA-Compliant DMU Fuel Tank Analyses}

An FRA-compliant Diesel Multiple Unit (DMU) railcar fuel tank was the first fuel tank analyzed. The DMU is a double-deck commuter car whose fuel tank is located below the side sill, approximately centered between the trucks. Figure 4 shows the side and bottom views of the railcar, with the fuel tank highlighted in red.
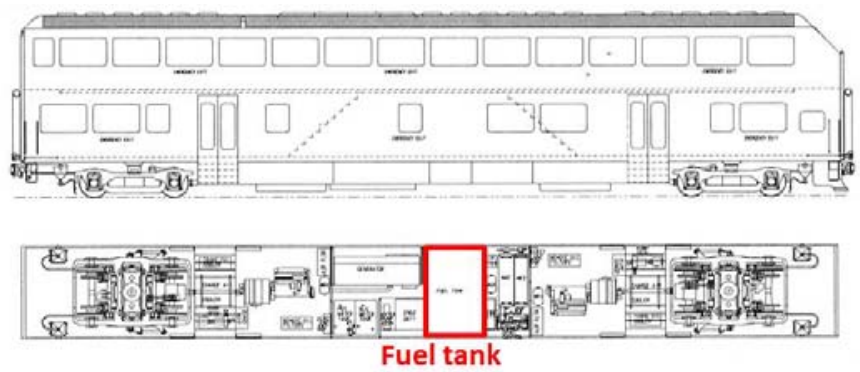

Figure 4. DMU, side view \& bottom view

The fuel tank is compliant with 49CFR238 Appendix D, "Requirements for External Fuel Tanks on Tier I Locomotives" [3]. The fuel tank body, shown in Figure 5, is constructed entirely out of $80 \mathrm{ksi}$ yield strength (90ksi ultimate strength) steel plates. A 4-inch tall, doubler plate is welded to the end plate at the bottom. There is a transverse baffle at the longitudinal midpoint of the tank. To satisfy the Code of Federal Regulations (CFR) Load Case 3 for a load to the side, a doubler plate, internal stiffeners, and internal gussets were added to each side of the tank. Seven longitudinal stiffener bars are welded to the bottom of the tank. The bars are A36 steel and span the entire length of the tank. The bars were installed to help distribute the load in the CFR Load Case 2 requirement, which requires the fuel tank to support half the weight of the locomotive on a specified area to approximate a derailed locomotive resting on the rails via the fuel tank. The empty tank weighs approximately 2300 lbs, with a capacity of approximately 587 gallons. The tank is connected to the DMU carbody at flanges off of the side sills and center sill of the underframe.

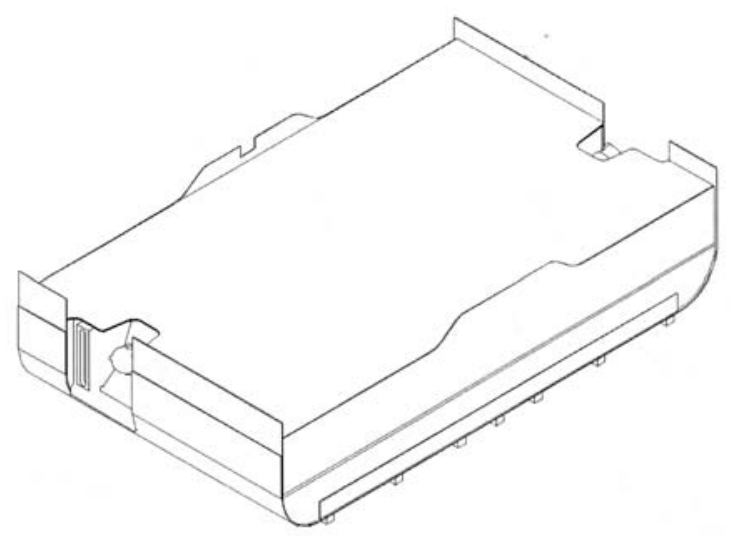

Figure 5. Isometric view of DMU fuel tank

This material is declared a work of the U.S. Government and is not subject to copyright protection in the United States. Approved for public release; distribution is unlimited. 
A FE model of the fuel tank was constructed and is shown in Figure 6 and Figure 7. Figure 7 shows the interior of the fuel tank, the location of the center baffle and internal stiffeners and gussets. The FE model contains approximately 36,000 shell and solid elements with a 1-inch characteristic element length. The tank was constrained at the tabs on the top, where they attach to the underframe of the railcar at the side sills and center sill.

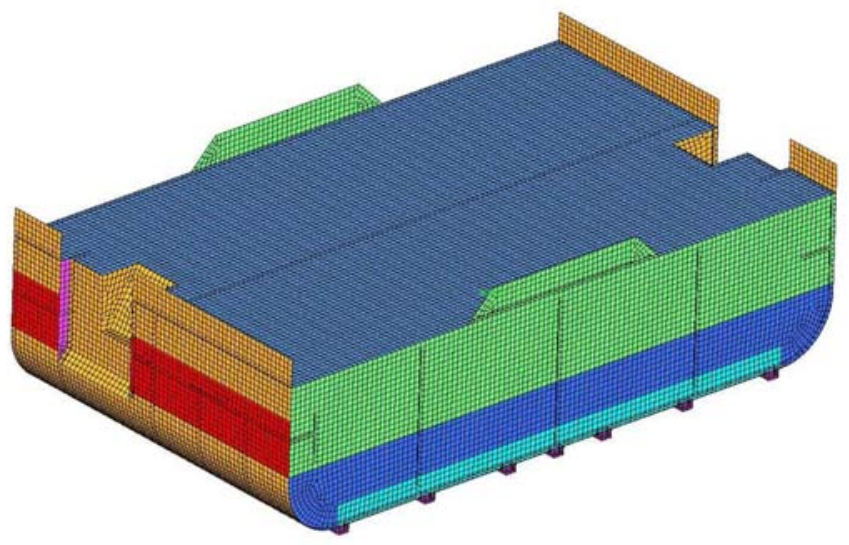

Figure 6. DMU fuel tank finite element model

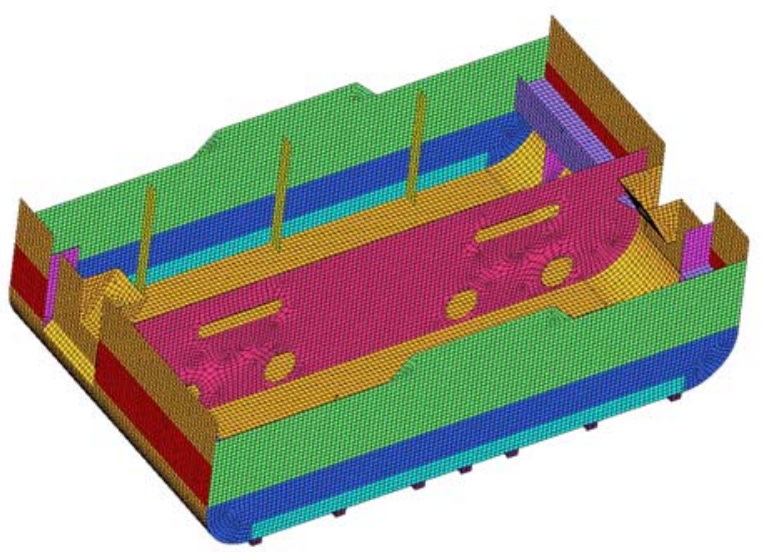

Figure 7. DMU fuel tank finite element model, interior view

Several finite element analyses were conducted with the tank using the commercial FE software Abaqus/Explicit [4]. In all analyses, the tank was constrained at the top and the tank bottom was subjected to impact from an initially-moving rigid impactor. Two different impactor geometries were included in the FE model:

- $\quad 3$ × 5 ” x $1 / 2$ " radius edges

- 12 ” 12 " x 1 ” radius edges

Different impactor sizes were used to investigate the effects of different-sized objects striking the fuel tank at the same location. The 3" x 5" impactor has approximately the same cross-sectional area as a railhead, and the 12" x12” impactor has approximately the same area as a coupler shank.

Two different masses were assigned to the impactors in the FE analyses:

- 14 kips

- 100 kips
Different masses were used to investigate the effects of different-massed objects striking the fuel tank at the same location. The 14-kip mass is the mass of a test cart that was used in dynamic tests of passenger car end frame structures [5] conducted to support the development of 49CFR238 Appendix $\mathrm{F}$ [3]. The 100-kip mass is the approximate mass of a passenger car.

Analyses were conducted with both impactor sizes and both masses with the impactor centered at the bottom of the tank. Centering the impactor positions it directly in-line with the central baffle, as shown in Figure 7. All of the analyses were conducted at an impact speed that just achieves puncture of the fuel tank. Puncture was defined as element failure of the model. When the equivalent plastic strain within an element reached $40 \%$, the element was removed from the analysis.

To understand the effect of changing the impactor location, and the effect of removing the stiffener bars from the tank bottom, more analyses were conducted with the smaller impactor (3” x 5”) and smaller mass (14 kips) in off-center Location A and Location B (shown in Figure 8), as well as with the stiffener bars removed from the bottom of the fuel tank:

- Location A

- Location B

- No Bars

In Figure 8, Location $\mathrm{A}$ is just off-center from the interior center baffle and just to the side of a tank bottom bar, and Location B is just to the side of a tank bottom bar and just to the side of the side of the tank.

A series of load cases were analyzed using this model to evaluate the effect of load position on the bottom surface. Figure 9 shows the deformed fuel tank impacted in the center by the 3"x5", 14-kip impactor. In this analysis, failure first occurs in the bottom of the tank where the corners of the impactor touch it. Figure 10 shows the deformed fuel tank impacted in the center by the 12”x12”, 100-kip impactor. In this analysis, failure occurs in the bottom of the tank at the corners and not near the impactor.

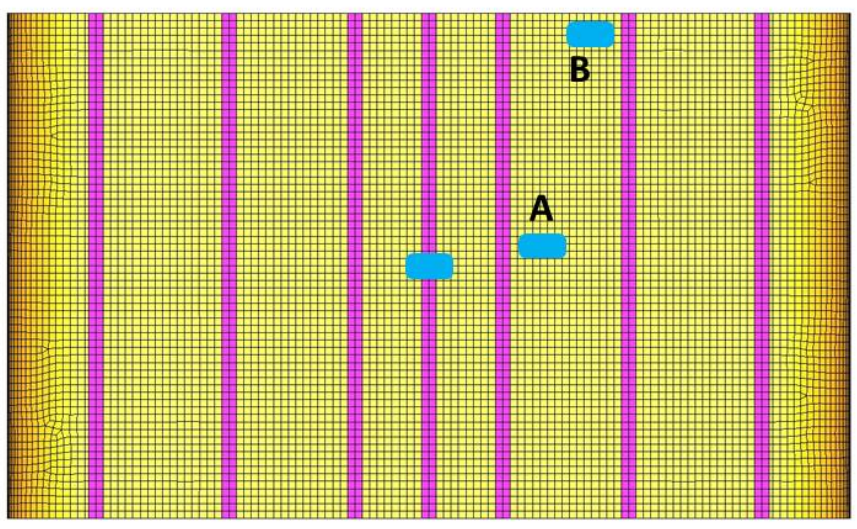

Figure 8. Bottom of fuel tank, impactor locations (centered, Location A \& Location B)

This material is declared a work of the U.S. Government and is not subject to copyright protection in the United States. Approved for public release; distribution is unlimited. 


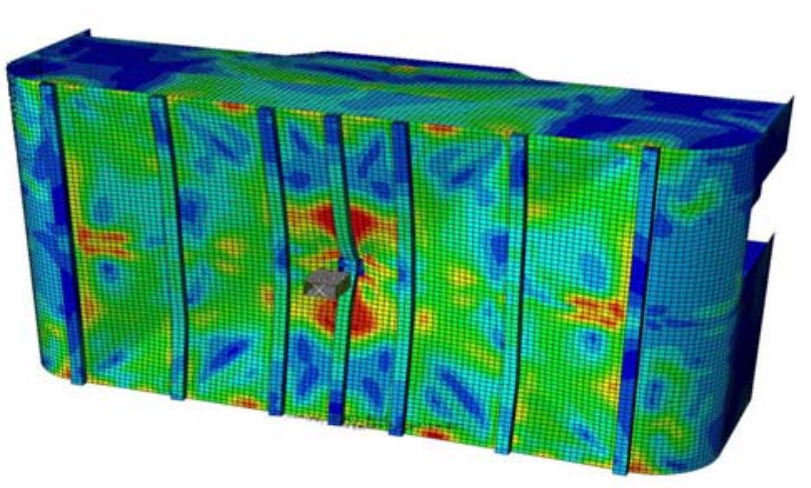

Figure 9. 3"x5", 14-kip impactor, centered impact

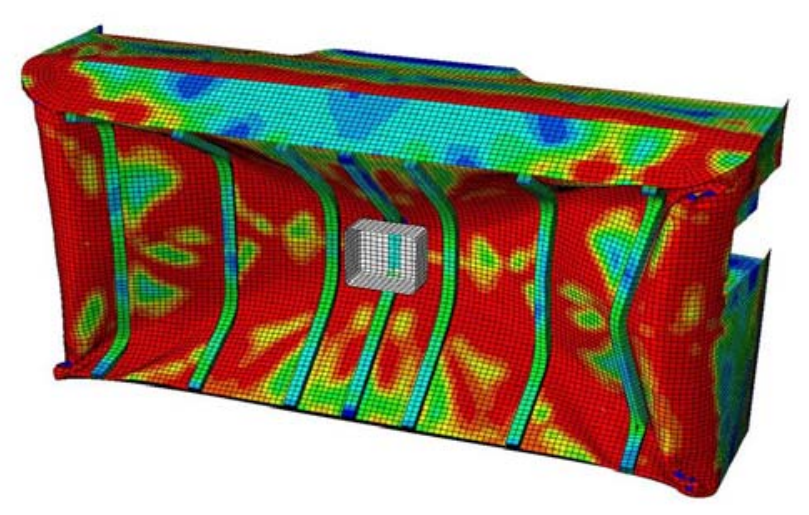

Figure 10. 12"x12", 100-kip impactor, centered impact

The nature of the deformation is different for the large impactor versus the small one. The small impactor concentrates the force on the tank center, causing failure at the center with little deformation of the rest of the tank. Whereas the large impactor distributes the force, allowing more of the tank bottom to deform, causing the failure to occur away from the impactor at the corners of bottom of the tank.

Qualitative force versus displacement plots are presented throughout this paper. Qualitative plots were selected to provide an estimation of the overall behavior of the tank under impact conditions. Using these preliminary results, the relative influence of the impact location and impacting object size on the response of the fuel tank can be compared. The energy required to puncture a given tank will require the input of more detailed material properties into the FE model as well as the potential for mesh refinement in the area surrounding the impactor. Further information on the arrangement of the interior baffles, including the sizes and locations of baffle cutouts, will also be used to refine the simulations. Additional simulations including this further level of detail are planned to be conducted prior to performing the planned impact tests.

Figure 11 shows a qualitative plot of impactor force versus displacement for the centered impactor analysis results.

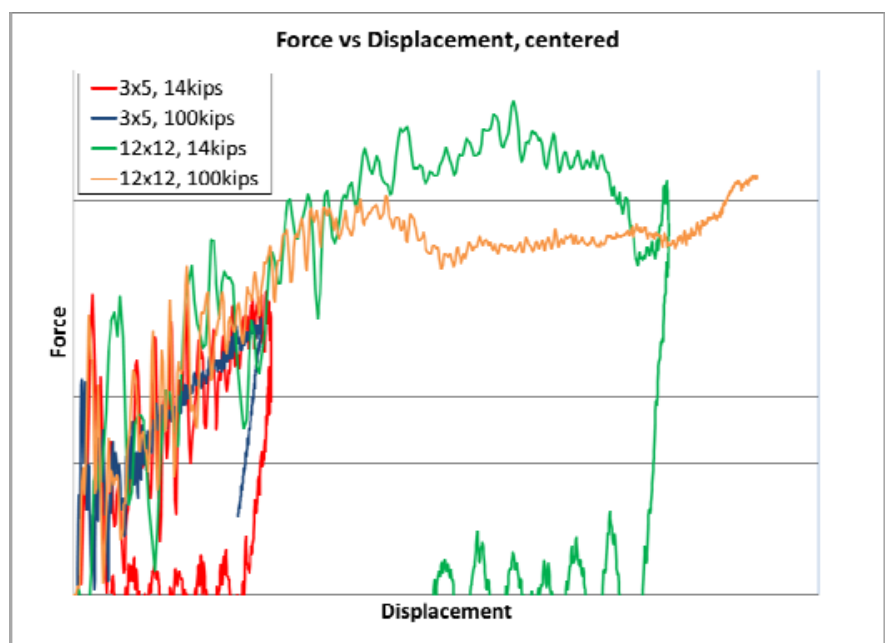

Figure 11. Qualitative Force vs. Displacement, centered impactors

For all of the impacts, there is an initial peak where the center baffle buckles. Then the force-displacement slope is approximately the same for all impacts. However, the small impactor cases puncture at a much lower displacement than the large impactor cases. As shown in Figure 11, the size of the impactor makes much more of a difference than the mass of the impactor.

Figure 12 shows the deformed fuel tank impacted in Location A by the 3"x5”, 14-kip impactor. This location is just to the side of the center baffle, as well as just to the side of a tank bottom stiffener. In this analysis, failure first occurs in the bottom of the tank where the impactor hits it, with very little deformation elsewhere in the tank. Figure 13 shows the deformed fuel tank with no stiffener bars impacted in the center by the 3"x5", 14-kip impactor. In this analysis, failure first occurs in the bottom of the tank where the impactor hits it, however much more of the tank is deformed.

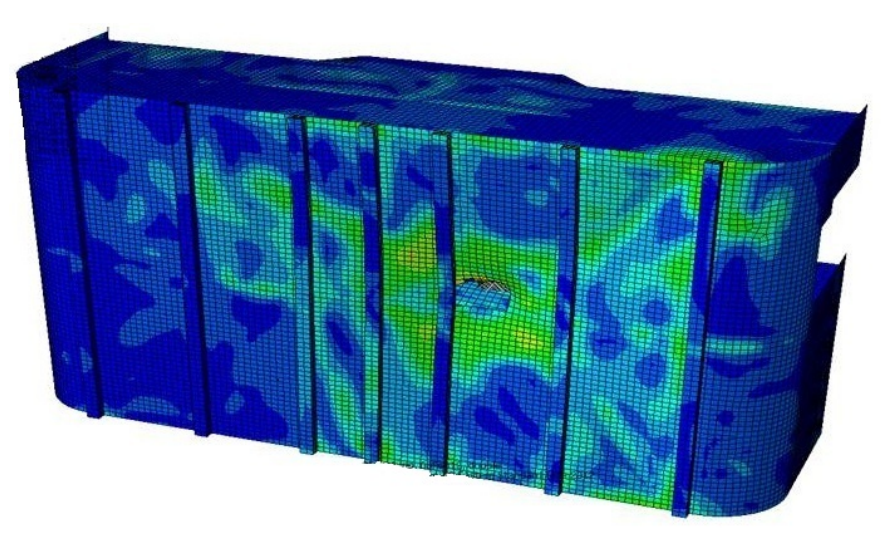

Figure 12. 3"x5", 14-kip impactor, Location A

The nature of the deformation is different for both of these impacts when compared to the impact in Figure 9. When the impactor just misses the baffle and the stiffener bars, it punctures the tank quickly, with very little deformation of the rest of the tank. When the stiffener bars are removed from the

This material is declared a work of the U.S. Government and is not subject to copyright protection in the United States. Approved for public release; distribution is unlimited. 
bottom of the tank, much more deformation and displacement of the tank occurs.

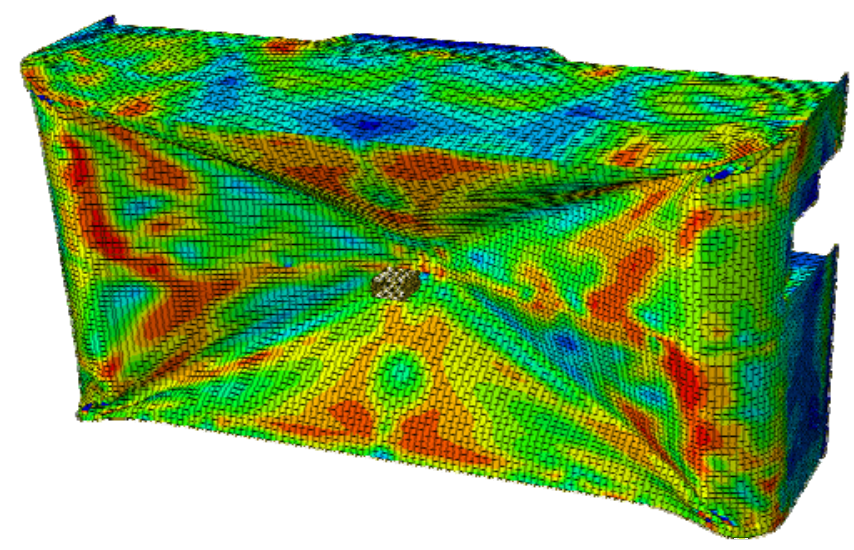

Figure 13. 3"x5", 14-kip impactor, no bars on tank bottom

Figure 14 shows a qualitative plot of impactor force versus displacement for analysis results with the impactor at various locations. As with Figure 11, for the two centered impacts (center and No Bars), there is an initial peak where the center baffle buckles. For the Location A load case, puncture occurs sooner than in the centered load case. For the Location B load case, puncture occurs almost immediately, with very little tank deformation involved. This location is next to the side wall of the tank. The force-displacement behavior indicates that the tank is much stiffer at Location B than at Location A.

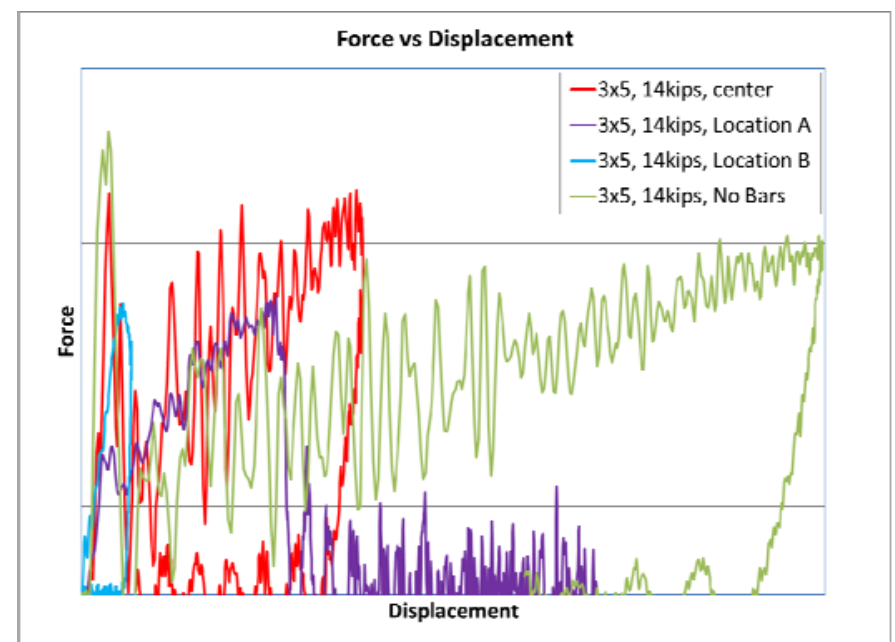

\section{Figure 14. Qualitative Force vs. Displacement, varying impactor locations}

In the No Bars load case, the displacement of the tank continues farther than all of the other load cases in Figure 14. This is understandable as the tank is more flexible without the bars stiffening the bottom of the tank, and there is more tank deformation as a result of the impact.

\section{Passenger Locomotive Fuel Tank Analyses}

Measurements of geometry and material properties were made for two fuel tanks currently installed on test locomotives at TTC in Pueblo, CO. Locomotives 232 and 202 are both
EMD F-40 type locomotives previously used in passenger service. The fuel tanks of these locomotives are of two different designs, with fuel tank 202 having square sides and fuel tank 232 having rounded sides. Figure 15 shows the fuel tank of locomotive 202 on the top and the fuel tank of locomotive 232 on the bottom.

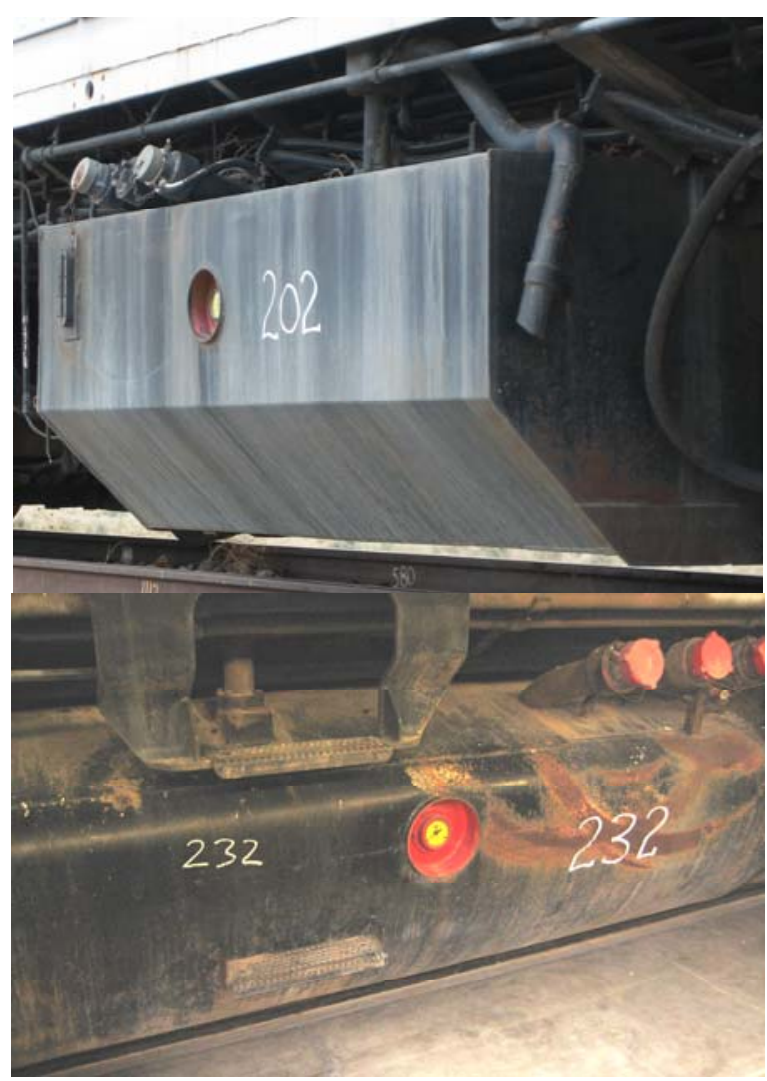

Figure 15. Fuel Tank 202 (top) and 232 (bottom)

Personnel from TTCI measured the exterior geometries of the two fuel tanks, estimated the locations of the interior baffles, estimated the thickness of material making up the accessible surfaces of the fuel tanks, and provided hardness measurements for the various sides of the fuel tank. It is envisioned that more detailed measurement of the material properties, including tensile testing of samples from various locations, will be conducted as part of this program. Additionally, detailed baffle geometry may be obtained following testing by cutting the tanks open during post-test examination.

The focus of the preliminary FE analyses was on understanding the qualitative behavior of the tanks. While tensile testing of materials from the tanks is planned for this research program, these material tests are currently planned to take place following the impact testing. This will allow the tanks to be tested intact, without having pieces removed to provide test coupons. Additionally, testing of the baffle material will require cutting away a sufficient portion of the outer tank to permit access.

Consequently, the material data used in the current models has been estimated from hardness measurements made on the tanks' outer surfaces. For steels, a relationship between 6

This material is declared a work of the U.S. Government and is not subject to copyright protection in the United States. Approved for public release; distribution is unlimited. 
hardness and tensile strength has been used to estimate the properties of the steel in the fuel tanks:

Tensile Strength (psi) = $515 \times$ (Brinnell Hardness) [6]

As an estimation of the yield strength of the material used, it was assumed that all materials had a yield strength that was $65 \%$ of the tensile strength. A bi-linear elastic, perfectly plastic (EPP) material property was defined within the FE analysis such that the steel exhibited elastic behavior up to the defined stress. At that point, the stress did not increase with increasing strain. When the equivalent plastic strain within an element reached $40 \%$, the element was removed from the analysis. In this way, the simple failure model would permit an estimation of whether the tank did or did not experience puncture during a given simulated impact condition. This simple estimation of puncture is used in the preliminary analyses. More detailed examination of the puncture behavior, including mesh refinement and variation of the strain-to-failure, are planned as a part of this research program.

FE models of Tanks 202 and 232 were built using the geometry and material estimations provided by TTCI. These FE models were assembled using Abaqus/CAE and simulation was performed using Abaqus/Explicit [4]. The FE model of tank 202 is shown on the top of Figure 16 and the FE model of tank 232 is shown at the bottom of this figure. In this figure, each tank has a portion of its exterior cut away to provide a view of the baffles within the tank.

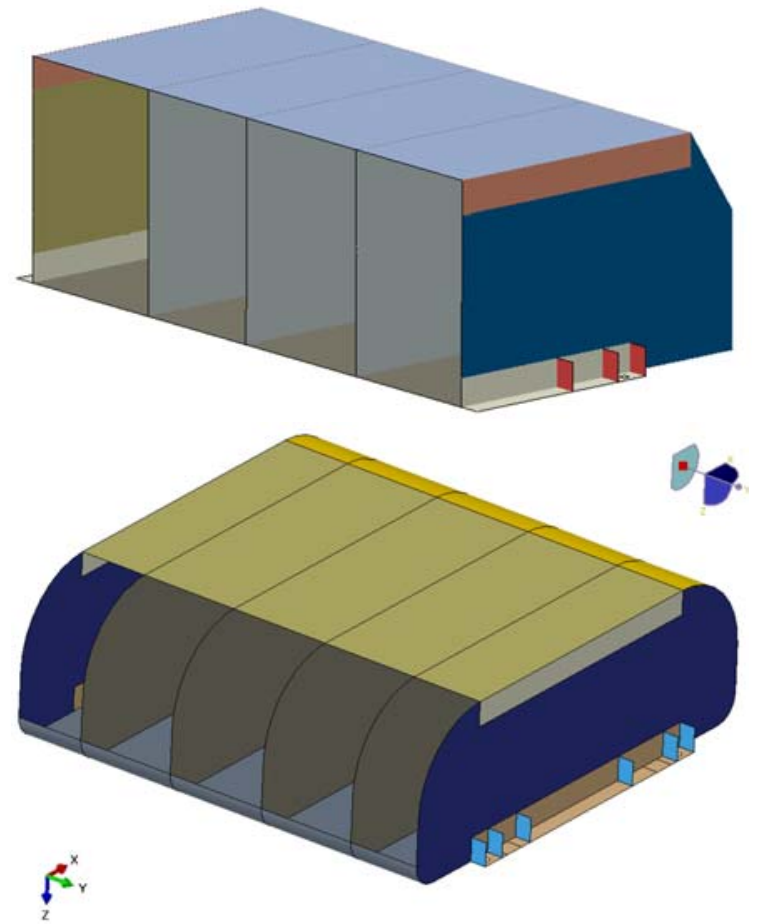

Figure 16. FE models of Tank 202 (top) and Tank 232 (bottom)

A series of FE analyses were conducted on each tank. In each simulation, the tank was positioned with its back against a rigid wall. The wall was not permitted to move during the analysis. The tank was restrained in each of the three principal directions through a zero-displacement boundary condition at each of its four bolt holes.

Each tank was subjected to impact from an initiallymoving rigid impactor. The impactor was given a mass corresponding to the 14-kip weight of the ram cart planned for use in the testing program. The impactor was constrained to allow motion only in the direction perpendicular to the wall. The impactor was also given a $10 \mathrm{mph}$ impact velocity for each impact case considered. The impactor, tank 202, and the rigid wall are shown in Figure 17 as an example of a typical analysis setup.

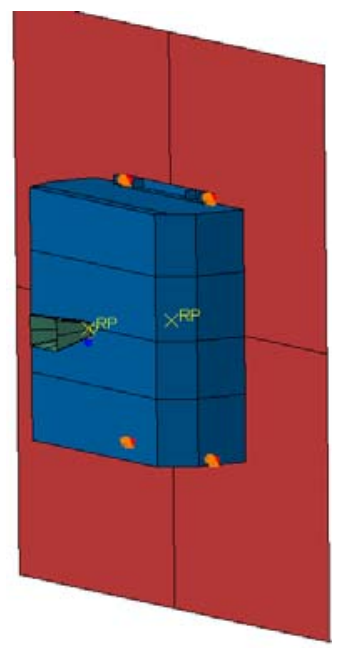

Figure 17. Impactor, Tank 202, and rigid wall in FE model

Three different impactor geometries were included in the FE model. These different impactor sizes were used to investigate the effects of different-sized objects striking the fuel tank at the same location. The three impactors that were simulated were:

$$
\begin{aligned}
& \text { - } \quad 3 \text { ” } 5 \text { " } \text { x } 1 / 2 \text { " radius edges } \\
& \text { - } 6 \text { " } \text { x } 6 \text { " } \text { x } 1 / 2 \text { " radius edges } \\
& \text { - } 12 \text { × } 12 \text { ” x } 1 \text { ” radius edges }
\end{aligned}
$$

In addition to examining the influence of the impactor size on the response of the fuel tank, various configurations of interior baffles have also been simulated. These configurations range from a tank with no interior baffles to a tank with a grid of lateral and longitudinal (relative to the tank in its operating position). The effect of impact occurring at different locations relative to the baffles has also been examined. Figure 18 shows several baffle configurations that were examined using simulation.
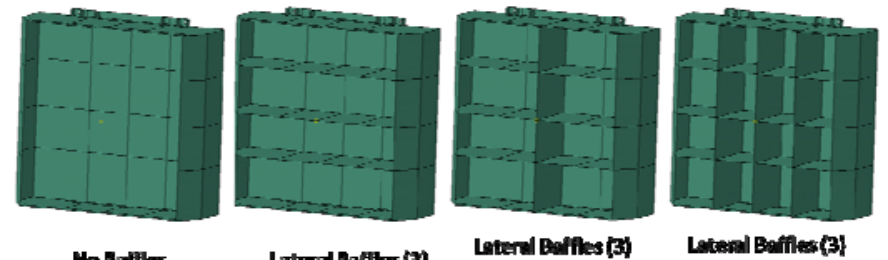

Lateral Rafiles (3)

Loterd Batles (B)

Ho Salifies gal Bafile:(1) Iongitudinal Bafiles (3)

Figure 18. Various interior baffle configurations examined

Figure 19 shows a qualitative plot of impactor force versus displacement for various analysis results. In each case, a 6” $\mathrm{x}$ 7

This material is declared a work of the U.S. Government and is not subject to copyright protection in the United States. Approved for public release; distribution is unlimited. 
6" impactor with an equivalent weight of 14 kips struck the fuel tank at the center of its bottom sheet at $10 \mathrm{mph}$. Each of the four baffle configurations shown in Figure 18 was simulated. For any impact case where baffles are present, an impact at the center of the tank loads the tank directly above either one or two baffles.

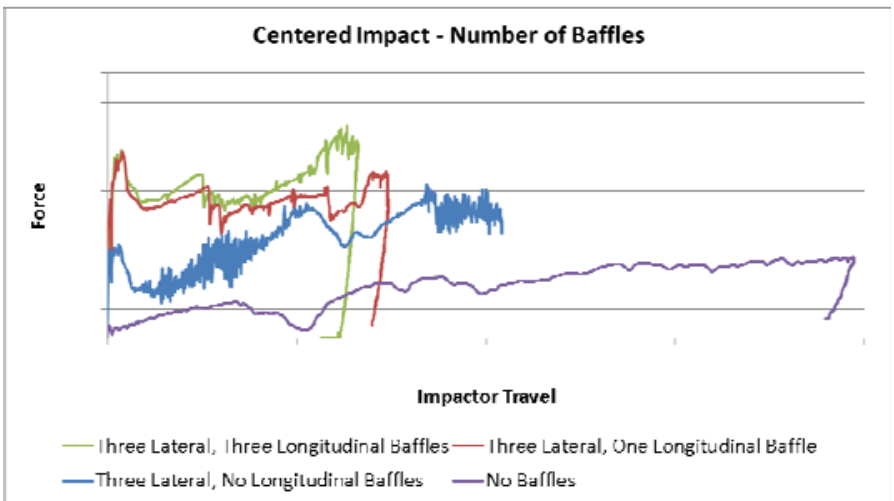

Figure 19. Qualitative plot of Force versus Impactor Travel for different baffle configurations

For the impact with no baffles within the tank, the forceversus-travel response is much softer than the other cases. Additionally, because of the additional flexibility in the tank the impactor does not puncture the bottom sheet of the tank for the chosen mass and initial velocity combination. For the three cases with at least one baffle directly beneath the impactor, the tank features an initial response with a steep slope and a peak. This behavior is associated with loading the baffle or baffles up to buckling. Once baffle buckling has occurred, the load continues to increase as travel increases, albeit at a decreased slope. For the load case with no longitudinal baffles, the tank is punctured before the impactor is stopped. For the cases with either one or three longitudinal baffles, the impactor does not puncture the tank for the chosen mass and initial velocity combination.

In addition to examining the influence of the number of baffles within the tank, preliminary analyses have been performed to examine the effect of striking the same tank either directly above a baffle or between several baffles. The arrangement of tank and impactor is shown in Figure 20 for the impact on top of the baffles and the impact between the baffles.

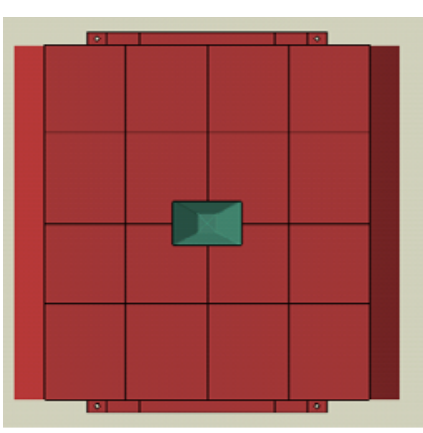

Impact at Baffles

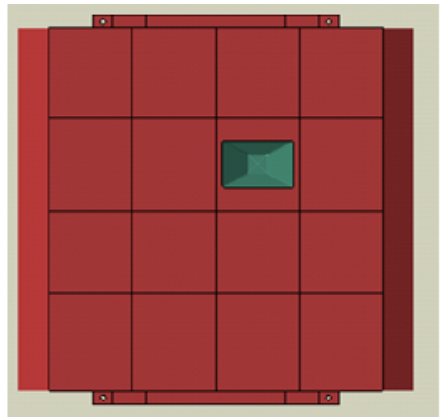

Impact between Baffles
Figure 20. Impact at baffles (left) and impact between baffles (right)
For this examination, the tank with the maximum number of baffles (three longitudinal, three lateral) was chosen. A 6” x 6” impactor with 14,000 pounds of weight struck the tank at an initial speed of $10 \mathrm{mph}$. The qualitative results of these two simulations are shown in Figure 21. The impact at the baffles exhibits a similar response to previous results where the fuel tank was impacted directly above the baffle, with a rapid initial rise in force followed by a drop as the baffle beneath the impactor is loaded to the point of buckling.

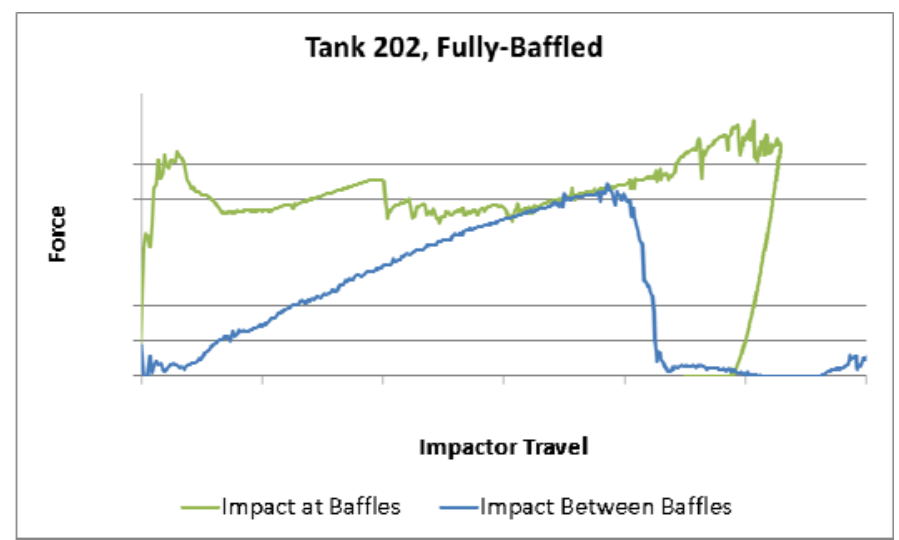

Figure 21. Qualitative plot of Force versus Impactor Travel for impacts at baffles and between baffles

When the impact occurs between baffles, the response of the tank is different from when the impact occurs directly on a baffle. When the impactor is centered between four baffles, the force-versus-travel response is much softer than the impact at a baffle. The tank deforms mainly through stretching of the bottom sheet, which is effectively supported by the baffles. For the given impact conditions, the bottom sheet does not puncture when the tank is struck at a baffle but does puncture when the tank is struck between baffles.

\section{TEST IMPLEMENTATION}

\section{Test Fixtures}

In the first planned fuel tank impact test, the tank is intended to be impacted at the bottom face. A fixture must be constructed to mount the fuel tank to the existing crash wall at TTC and allow the bottom panel to be struck in the desired location by the indenter. It is planned that the mounting fixture will utilize existing lifting lugs on the crash wall to support the fuel tank through its mounting bolt holes. Figure 22 shows a photograph of the test wall. Existing sets of lifting lugs are indicated with rectangles.

This material is declared a work of the U.S. Government and is not subject to copyright protection in the United States. Approved for public release; distribution is unlimited. 


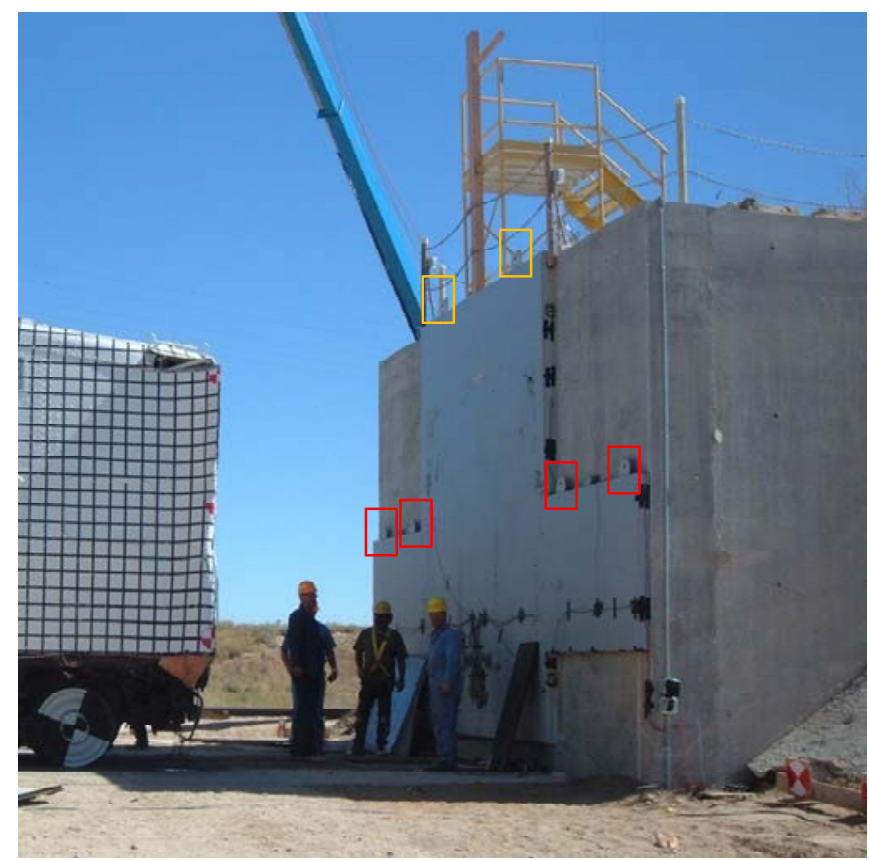

Figure 22. Test impact wall at TTC

A variety of indenter sizes and shapes have been considered for the planned testing. Three such impactors have been described in the previous section of this paper. Of the three impactors described, the 3" x 5" impactor would need to be constructed if it was desired for use in the impact tests. The 6" x 6” and 12 ” $\mathrm{x}$ 12 ” impactor geometries have both been constructed for use in previous impact testing. These two indenters are currently mounted to a modified railcar, which was used as a ram car in a set of tank car impact tests conducted at TTC [7, 8]. A second possible impact vehicle for the fuel tank testing program is a cart that was used for a set of end frame impact tests, also conducted at TTC [5]. The ram cart from the endframe test is shown in Figure 23.

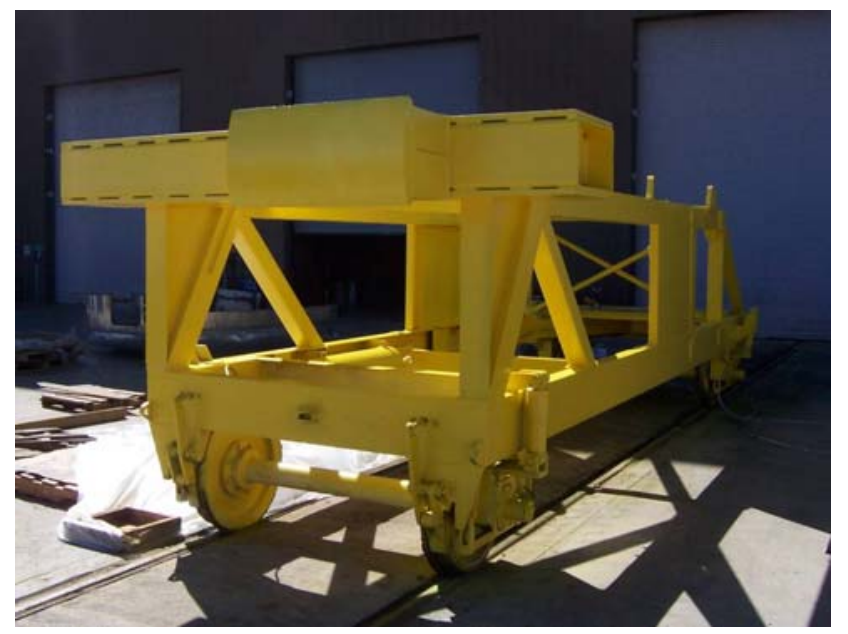

Figure 23. Ram cart planned for use in impact test

The ram car weighs approximately 300 kips and the ram cart weighs approximately 14 kips. The desired impact energy for the impact test will be achieved by adjusting the speed and the weight of the impactor, if necessary. The collision energy can be calculated as:

\section{Collision Energy $=1 / 2 \mathbf{~ m v}$}

Because the ram car weighs 300 kips, a relatively low impact speed is required to generate an impact with the same amount of energy as a higher-speed collision using the 14 kip impact cart. Because the practical range of impact speed for the impact cart is estimated to be 5 to $35 \mathrm{mph}$, the ram cart is seen as the more desirable impact vehicle for this test.

\section{Planned Instrumentation}

The key measurement to be made during this test is the impact force versus impactor displacement. Force transducers will be mounted at each location the fuel tank and braced against the crash wall. The impact cart will be instrumented with accelerometers and speed sensors to measure the gross motions of the cart and indenter as shown in Figure 24. The accelerometer data will be used to derive the force and relative displacement data from the test as well. High speed cameras will be placed with oblique and head-on views to record the test.

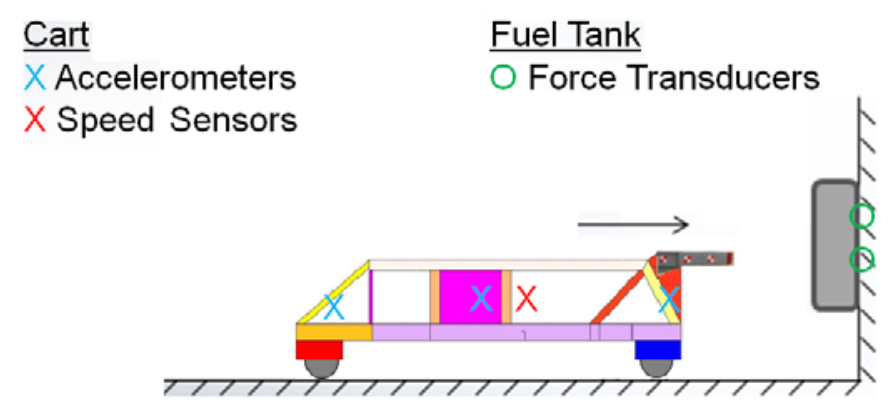

Figure 24. Schematic showing test setup and preliminary plans for instrumentation

\section{Data Acquisition}

The primary output of this test will be the force-deflection behavior of the bottom face of the fuel tank. The force will be determined by reviewing both the force transducer values and the acceleration of the indenter mounted to the cart. The deflection of the bottom face will be measured by determining the intrusion of the indenter.

\section{Test Procedures}

For each of the two tests, the fuel tanks shown in Figure 15 will be emptied and mounted to the crash wall at a height that will allow the indenter to strike at the desired location. The indenter will be securely mounted to the cart and the lateral location of the indenter will be adjusted to allow it to strike the target location on the bottom face of the fuel tank. The cart will be released so that it strikes the fuel tank at the desired speed. Weight may need to be added to the cart to achieve the desired collision energy based upon the achievable range of speeds. Details of collision speed, cart mass and impact location are currently in discussion with the test center.

This material is declared a work of the U.S. Government and is not subject to copyright protection in the United States. Approved for public release; distribution is unlimited. 


\section{SUMMARY}

Fuel tank research is being conducted to determine strategies for decreasing the likelihood of tank rupture and the resultant threat of a post-collision or derailment fire. Existing regulations require that fuel tanks support static loads without failure. Current research is focusing on understanding the impact response of the fuel tanks under dynamic loading.

A recent accident survey conducted of rail collisions or derailments resulting in breached fuel tanks identified two types of impacts that cause punctures: blunt impacts and raking impacts. Blunt impacts are caused by a focused impact by an adjacent truck, underframe component or another railcar that deforms and pierces through the tank surface. A raking collision occurs when a hard structure drags along the surface of the fuel tank, causing a tearing of the tank.

Utilizing the same approach that has been effective in increasing the structural crashworthiness of passenger railcars, improved strategies can be developed that will address the types of loading conditions experienced in a collision or derailment event. This information can be used to develop performance-based requirements, which address known safety hazards and can typically be applied to a wide range of fuel tank designs and equipment.

Three fuel tank designs were modeled and analyzed to characterize the deformation of fuel tanks under a blunt impact. The model results helped to identify the influence of various test parameters such as impactor size, location of impact, and required collision energy to deform the tank. Results show that the location of the impact relative to the stiffeners, baffles, etc., and the impactor size influence the energy-to-rupture of each tank.

Test preparations for the first tests of two conventional passenger locomotive fuel tanks are currently underway. Test fixtures are being designed and built at TTC. Test instrumentation is being specified according to model predictions to obtain measurements of force-deflection characteristics of each fuel tank. Tests are targeted for summer 2013.

\section{FUTURE PLANS}

The following table shows the series of tests planned for investigating fuel tank performance under dynamic loading conditions:

Table 2. Future Fuel Tank Test Plans

\begin{tabular}{|c|c|c|c|c|}
\hline & \multicolumn{2}{|c|}{ Conventional Fuel Tank } & \multicolumn{2}{|c|}{ Alternative Designs } \\
\hline & $\begin{array}{l}\text { Passenger } \\
\text { Locomotive }\end{array}$ & DMU & $\begin{array}{l}\text { Passenger } \\
\text { Locomotive }\end{array}$ & DMU \\
\hline $\begin{array}{l}\text { Blunt } \\
\text { Impact }\end{array}$ & $\begin{array}{l}\text { Summer } \\
2013\end{array}$ & $\begin{array}{l}\text { Winter } \\
2014\end{array}$ & $\begin{array}{l}\text { Summer } \\
2015\end{array}$ & $\begin{array}{l}\text { Winter } \\
2016\end{array}$ \\
\hline $\begin{array}{l}\text { Raking } \\
\text { Impact }\end{array}$ & $\begin{array}{l}\text { Summer } \\
2014\end{array}$ & Fall 2014 & Fall 2015 & $\begin{array}{l}\text { Summer } \\
2016\end{array}$ \\
\hline
\end{tabular}

The dates shown above are estimates. The key influencing factor in the conduct of these tests is obtaining fuel tanks for testing. A broader range of fuel tank designs will enable a more comprehensive understanding of the dynamic response of existing fuel tank designs.

\section{ACKNOWLEDGEMENTS}

The research discussed in this paper was performed as part of the Equipment Safety Research Program sponsored by the Office of Research and Development of the FRA. Melissa Shurland, Program Manager, Office of Railroad Policy and Development, manages this research effort. Jeff Gordon, Program Manager, Office of Railroad Policy and Development, provides technical advice and logistical support. Kevin Kesler, Chief, Equipment and Operating Practices Division, reviewed and supported this effort. Luis Maal, Resident Engineer Program Manager at TTC, coordinates effort between FRA, Volpe and TTCI.

The authors would like to acknowledge colleagues, David Tyrell and Benjamin Perlman of the Volpe National Transportation Systems Center for their ongoing technical advice and support in the research discussed in this paper.

\section{REFERENCES}

[1]. Minnick, B., Smith, K., "Train, Tractor-trailer Wreck Injures 13, Disrupts Amtrak Service,” Capitol Broadcasting Company, 2011. www.wral.com/news/local/story/7593803/

[2]. Jacobsen, K., "Fuel Tank Crashworthiness: Loading Scenarios," American Society of Mechanical Engineers, Paper No. JRC2011-56077, March 2011.

[3]. U.S. Department of Transportation, Federal Railroad Administration, Code of Federal Regulations, Title 49, Part 238, Appendix D- "Requirements for External Fuel Tanks on Tier I Locomotives".

[4]. Abaqus version 6.12. Dassault Systems Simulia Corp, Providence, RI, 2012.

[5]. Muhlanger, M., Llana, P., Tyrell, D. "Dynamic and QuasiStatic Grade Crossing Collision Tests" American Society of Mechanical Engineers, Paper No. JRC2009-63035, March 2009.

[6]. "Hardness.” Center for Advanced Life Cycle Engineering - Test Services and Failure Analysis Laboratory. Accessed 12/17/2012. http://www.calce.umd.edu/TSFA/Hardness_ad_.htm

[7]. Carolan, M., Talamini, B., Tyrell, D., "Update on Ongoing Tank Car Crashworthiness Research: Predicted Performance and Fabrication Approach," Proceedings of the 2008 IEEE/ASME Joint Rail Conference, JRC200863052, April 2008.

[8]. Tang, Y.H., Yu, H., Gordon, J.E., Jeong, D.Y., Perlman, A.B., "Analysis of Railroad Tank Car Shell Impacts Using Finite Element Method," Proceedings of the 2008 IEEE/ASME Joint Rail Conference, JRC2008-63014, April 2008.

This material is declared a work of the U.S. Government and is not subject to copyright protection in the United States. Approved for public release; distribution is unlimited. 